\title{
Rediscovering Trazodone for the Treatment of Major Depressive Disorder
}

\author{
Andrea Fagiolini $\cdot$ Alessandro Comandini $\cdot$ \\ Mario Catena Dell'Osso • Siegfried Kasper
}

Published online: 13 October 2012

(c) The Author(s) 2012. This article is published with open access at Springerlink.com

\begin{abstract}
Trazodone is a triazolopyridine derivative that belongs to the class of serotonin receptor antagonists and reuptake inhibitors (SARIs). The drug is approved and marketed in several countries worldwide for the treatment of major depressive disorder (MDD) in adult patients. In clinical studies, trazodone has demonstrated comparable antidepressant activity to other drug classes, including tricyclic antidepressants (TCAs), selective serotonin reuptake inhibitors (SSRIs) and serotonin-noradrenaline (norepinephrine) reuptake inhibitors (SNRIs). Moreover, the SARI action of trazodone may overcome the tolerability issues that are often associated with second-generation antidepressants such as SSRIs (i.e. insomnia, anxiety and sexual dysfunction). Recent focus has been placed on the development of a new prolonged-release once-a-day formulation of trazodone (TzCOAD), which may provide improved tolerability over the conventional immediate-release formulation of trazodone. Clinical studies have led to the recent approval in the USA of TzCOAD (as Oleptro ${ }^{\mathrm{TM}}$; Angelini Labopharm LLC, Princeton, NJ, USA), which
\end{abstract}

A. Fagiolini ( $\square)$

Division of Psychiatry, Department of Molecular Medicine,

University of Siena School of Medicine,

Viale Bracci 1, Siena, Italy

e-mail: andreafagiolini@gmail.com

\section{A. Comandini}

Angelini (ACRAF SpA), Pomezia, Rome, Italy

\section{C. Dell'Osso}

Psychiatric Unit, Department of Experimental and Clinical Medicine, Polytechnic University of Marche, Ancona, Italy

\section{S. Kasper}

Vorstand, Universitatsklinik fur Psychiatrie und Psychotherapie Medizinische Universitat Wien, AKH, Vienna, Austria may see resurgence of interest in the drug for the management of patients with MDD. Although trazodone is approved for the treatment of depression, evidence supports the use of low-dose trazodone as an off-label hypnotic for the treatment of sleep disorders in patients with MDD. The most common adverse effects reported with trazodone are drowsiness (somnolence/sedation), headache, dizziness and dry mouth. Other events reported, albeit with low incidence, include orthostatic hypotension (particularly in elderly patients or those with heart disease), minimal anticholinergic activity, corrected QT interval prolongation and torsade de pointes, cardiac arrhythmias, and rare occurrences of priapism and suicidal ideation. Overall, trazodone is an effective and well tolerated antidepressant (SARI) with an important role in the current treatment of MDD both as monotherapy and as part of a combination strategy. Trazodone is effective in controlling a wide range of symptoms of depression, while avoiding the negative effects on sleep seen with SSRI antidepressants. The recently approved prolonged-release formulation should provide further optimization of this antidepressant and may be useful for enabling an appropriate therapeutic dose to be administered with improved patient compliance.

\section{Introduction}

Major depressive disorder (MDD) is a common mental disorder that affects approximately 121 million people worldwide, and is among the leading causes of disability and disease burden [1]. In primary care, MDD can be reliably diagnosed and international treatment guidelines along with various algorithms are available to guide physicians in the treatment process [2]. Despite the availability 
of antidepressant pharmacotherapies that could provide effective and well tolerated treatment to many patients, fewer than $25 \%$ of individuals with MDD receive adequate treatment $[1,3]$.

According to current treatment guidelines, the main goals of treatment for MDD include the achievement of symptomatic remission and function recovery [4-8]; however, suboptimal treatment prevents the achievement of these goals [9]. In general, the first-line treatment of moderate or severe MDD includes antidepressant monotherapy, evidence-based psychotherapy and/or a combination of both approaches [4-8]. Patients with severe MDD may require the combination of an antidepressant with an antipsychotic agent, electroconvulsive therapy or a combination of antidepressant(s) with psychotherapy [4-8]. Furthermore, treatment strategies for patients who have not responded adequately to first-line therapy include switching to a different monotherapy, combination therapy with another antidepressant or augmentation with a different agent [6].

Over 20 years has passed since the introduction of the last major class of antidepressant medications, the selective serotonin reuptake inhibitors (SSRIs), which are now widely available. SSRIs and their derivative compounds, the serotonin-noradrenaline (norepinephrine) reuptake inhibitors (SNRIs) and noradrenaline reuptake inhibitors (NERIs), have since been shown to be comparable in efficacy and more tolerable than older agents such as tricyclic antidepressants (TCAs) and monoamine oxidase inhibitors (MAOIs) [10]. However, significant therapeutic limitations exist, including modest remission rates, often $<50 \%$ for both SSRIs and SNRIs [11], a relatively slow onset of efficacy [12] and variable efficacy across the spectrum of depressive symptoms [13]. Furthermore, adverse effects are common, including sexual dysfunction [14], weight gain/loss [15], insomnia/daytime sleepiness [16-18] and anxiety or nervousness [17].

Trazodone is a serotonin antagonist and reuptake inhibitor (SARI) that has been available for the treatment of MDD with or without anxiety since the early 1970s [19]. The agent is generally well tolerated, with fewer anticholinergic effects than imipramine and amitriptyline and has comparable antidepressant efficacy to other second-generation antidepressants [20]. Other marketed SARIs include other phenylpiperazine antidepressant/anxiolytic agents, etoperidone, lorpiprazole and mepiprazole.

Trazodone is available in many countries worldwide in different formulations including immediate-release (IR) tablets, prolonged-release tablets and, in some countries, even as oral drops and solution for injection.

A novel, prolonged-release, once-a-day formulation of trazodone (150- and 300-mg bisectable tablets), utilizing Contramid $^{\circledR}$ (Angelini Labopharm LLC, Princeton, NJ, USA) drug-delivery technology (trazodone Contramid ${ }^{\circledR}$ once-a day [TzCOAD]), has been recently developed. This proprietary delivery technology is able to control the release of trazodone over $24 \mathrm{~h}$ and was developed in an attempt to enhance patient compliance to therapy without a loss in efficacy and to improve tolerability by avoiding the early high peak plasma concentration seen with conventional IR formulations. TzCOAD was approved in the USA in early 2010 for the treatment of patients with MDD (Oleptro ${ }^{\mathrm{TM}}$; Angelini Labopharm LLC) and it is undergoing approval in many European countries [21].

Due to its combined serotoninergic receptor antagonism and serotonin reuptake inhibition (SARI), trazodone has also demonstrated unique therapeutic flexibility [22], which has given rise to its potential use in a broad range of co-morbidities associated with MDD as well as off-label indications, including insomnia, anxiety, dementia, Alzheimer's disease, substance abuse, schizophrenia, bulimia and fibromyalgia.

The aim of the current publication is to review the more recent clinical data for trazodone in MDD, focusing on the approved dose of $300 \mathrm{mg} / \mathrm{day}$, and to discuss its place in current treatment strategies for MDD and related conditions and for off-label indications insomnia and anxiety.

A literature search was conducted in PubMed/MEDLINE using the following keywords: 'trazodone' and 'major depressive disorder' as free text. The search was limited to fully published, randomized controlled trials, English-language only. Each paper was assessed for relevance, and only articles published after 1981 (US approval date) were included. Separate searches were conducted for the use of trazodone in other indications including insomnia and anxiety. Again, only fully published, randomized controlled trials were included.

\section{Mechanisms of Action and Pharmacological Properties of Trazodone}

Trazodone is a triazolopyridine derivative (Fig. 1) [23]. Although its pharmacological actions in humans are not fully understood, trazodone is thought to have more than one mechanism of therapeutic action, making it a multifunctional drug [22].

\subsection{Trazodone: A Serotonin Receptor Antagonist and Reuptake Inhibitor (SARI) Antidepressant}

Trazodone is the first antidepressant with a dual mechanism of action involving inhibition of the serotonin transporter (SERT) and serotonin type $2\left(5-\mathrm{HT}_{2}\right)$ receptor antagonism (both the 5- $\mathrm{HT}_{2 \mathrm{~A}}$ and $5-\mathrm{HT}_{2 \mathrm{C}}$ receptors) [22]. Preclinical evidence suggests that the antidepressant 


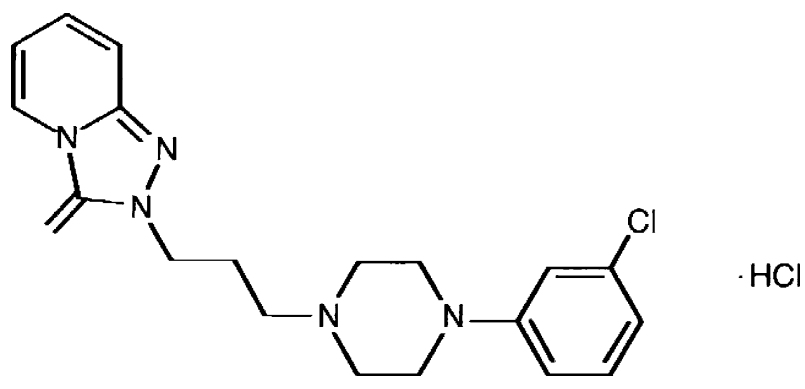

Fig. 1 Structural formula of trazodone

activity of SSRIs and SNRIs is most likely through blockade of the SERT, which results in serotonin exerting its agonistic actions on the $5-\mathrm{HT}_{1 \mathrm{~A}}$ receptor $[24,25]$. However, this agonistic effect of serotonin also acts on other serotonin receptor subtypes such as the $5-\mathrm{HT}_{2 \mathrm{~A}}$ and $5-\mathrm{HT}_{2 \mathrm{C}}$ receptors, which are thought to be responsible for the adverse effects often associated with SSRI and SNRI therapy, including insomnia, sexual dysfunction and anxiety [22]. Unlike SSRIs and SNRIs, SARIs such as trazodone provide simultaneous inhibition of SERT and 5- $\mathrm{HT}_{2 \mathrm{~A}}$ and $5-\mathrm{HT}_{2 \mathrm{C}}$ receptor antagonism, thus avoiding the tolerability issues often associated with $5-\mathrm{HT}_{2 \mathrm{~A} / 2 \mathrm{C}}$ stimulation. Furthermore, there have been suggestions that simultaneous $5-\mathrm{HT}_{2 \mathrm{~A} / 2 \mathrm{C}}$ antagonism and SERT inhibition may have a synergistic effect that potentiates the antidepressant activity of SARIs and may improve treatment tolerability [22, 24-28].

Moreover, trazodone exerts antagonistic properties against $\alpha_{1}$ - and $\alpha_{2}$-adrenergic receptors and histamine $H_{1}$ receptors, with minimal anticholinergic effects. It is also well known that at low doses (25-100 mg), trazodone has therapeutic activity as a hypnotic $[9,22]$. The actions of several neurotransmitter systems, including serotonin, noradrenaline, dopamine, acetylcholine and histamine, are known to be involved in arousal mechanism [25, 29, 30]. Therefore, arousal can be effectively impaired and sleep induced by inhibiting several of these neurotransmitter systems. The efficacy of trazodone in this regard may be explained by its ability to inhibit $\mathrm{H}_{1}$ receptors, and the sleep-inducing effect of $\mathrm{H}_{1}$ receptor blockade may be enhanced by simultaneous $5-\mathrm{HT}_{2 \mathrm{~A}}$ and $\alpha$-adrenergic receptor antagonism [25, 29, 30].

\subsection{Dosage and Administration}

According to the appropriate trazodone summary of product characteristics (SPC) [31-33], therapy should begin with an evening administration (starting dose $75-150 \mathrm{mg}$ before bedtime). Subsequently, the dose can be increased every 3 days up to $300 \mathrm{mg} /$ day, to be administered in repeated doses after meals (trazodone IR), two times a day (trazodone prolonged release) or once a day, preferably at bedtime (TzCOAD). In hospitalized patients the dose may be further increased up to $600 \mathrm{mg} /$ day in repeated doses. For elderly patients, the starting dose should be reduced to $100 \mathrm{mg} /$ day.

\subsection{Prolonged-Release Formulations}

A prolonged-release tablet formulation of trazodone (Roussel Laboratories Ltd., Guildford, UK) [75- and 150-mg tablets] was developed in the 1980s to limit the early and relatively high peak plasma drug concentrations that are seen with the IR tablets. This high peak plasma concentration may be associated with the occurrence of adverse effects such as somnolence or hypotension, especially during the first week of treatment. These adverse effects might limit the treatment tolerability and compliance, thus limiting the use of a therapeutic dose (up to $300 \mathrm{mg} /$ day) in patients with depression [34].

As reported in the SPC, after a single oral dose of $100 \mathrm{mg}$ of trazodone IR, a maximum plasma drug concentration $\left(\mathrm{C}_{\max }\right)$ of $1.2 \mu \mathrm{g} / \mathrm{mL}$ is reached with a time to

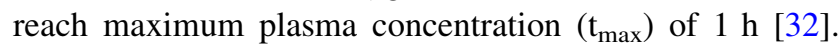
For trazodone prolonged release, after a single oral dose of $75 \mathrm{mg}$, a $\mathrm{C}_{\max }$ of around $0.7 \mu \mathrm{g} / \mathrm{mL}$ is reached, with a $\mathrm{t}_{\max }$ of $4 \mathrm{~h} \mathrm{[31].} \mathrm{After} \mathrm{a} \mathrm{single} \mathrm{oral} \mathrm{dose} \mathrm{of} 150 \mathrm{mg}$ of trazodone prolonged release, a $\mathrm{C}_{\max }$ of around $1.2 \mu \mathrm{g} / \mathrm{mL}$ is reached with a $t_{\max }$ at $4 \mathrm{~h}$ after administration [31]. The half-life is approximately $12 \mathrm{~h}$ [31].

The elimination half-life of trazodone IR is relatively short ( $6.6 \mathrm{~h}$ after a single 100-mg dose), therefore, repeated daily administrations are often used in order to achieve a sufficient dose level for MDD patients, but such a dosing regimen can be inconvenient, and can lead to missed doses and reduced compliance.

More recently, a new once-a-day, prolonged-release formulation of trazodone (TzCOAD, Oleptro ${ }^{\mathrm{TM}}$ ) was developed with the aim of further enhancing treatment compliance at therapeutic doses, and reducing the plasma peak concentration and dosing frequency compared with the conventional IR formulation [35]. TzCOAD was developed in two strengths (150- and 300-mg scored tablets) in order to allow for proper titration starting from $150 \mathrm{mg} /$ day, with $75 \mathrm{mg}$ increments every 3 days.

\section{Traditional Role of Trazodone in the Treatment of Major Depressive Disorder (MDD)}

Since the approval of trazodone, the drug has demonstrated comparable antidepressant activity to other drug classes such as TCAs, SSRIs and SNRIs in several clinical studies [36]. As a result, trazodone may be administered as 
monotherapy or in combination with other antidepressant medications for the treatment of MDD [4].

Despite its established efficacy and popularity as an antidepressant in the USA during the 1980s, current treatment guidelines state that trazodone IR is now more likely to be used at lower doses as a sedative-hypnotic rather than as an antidepressant in the USA [4]. However, there are limited clinical data to support the use of trazodone for this indication and trazodone continues to be approved solely for the treatment of MDD in the USA and the majority of countries worldwide.

Over the last few years, focus has been placed on the development of the new prolonged-release, once-a-day formulation of trazodone, with the aim to optimize its antidepressant efficacy, and improve the treatment schedule and compliance in MDD patients.

Due to its multifunctional pharmacology, appropriate dosing is indeed crucial to optimize clinical efficacy in patients with MDD.

\section{Efficacy and Tolerability of Trazodone in MDD}

Several head-to-head studies have demonstrated the comparable antidepressant efficacy between trazodone and other drug classes, including TCAs (amitriptyline and imipramine), SSRIs (fluoxetine, paroxetine, sertraline, citalopram and escitalopram), SNRIs (venlafaxine and mirtazapine) and noradrenaline and dopamine reuptake inhibitors (bupropion). Randomized, controlled clinical trials of trazodone in non-elderly adults with MDD published from 1981 are summarized in Table 1 [37-50].

\subsection{Trazodone Versus Tricyclic Antidepressants (TCAs)}

In a number of comparative trials conducted in the 1980s, short-term therapy (4-6 weeks) with trazodone $(100-400 \mathrm{mg})$ appeared to be comparable in efficacy to TCAs such as amitriptyline and imipramine [51-53]. An early randomized, double-blind, placebo-controlled study of geriatric patients with unipolar depression demonstrated that the therapeutic efficacy of trazodone was superior to placebo and comparable to imipramine after 4 weeks of treatment [53]. A double-blind, randomized study of trazodone in elderly patients with major depression reported significant improvements in the total Hamilton Rating Scale for Depression (HAM-D) and Geriatric Depression Scale (GDS) scores, which were similar to outcomes seen in patients treated with amitriptyline and mianserin [51]. Furthermore, HAM-D and Visual Analogue Scale (VAS) scores were similar between trazodone and amitriptyline in a study of elderly patients with depression [52].
4.2 Trazodone Versus Second-Generation Antidepressants

Several head-to-head trials have been conducted between trazodone (dose range 150-450 mg) and second-generation antidepressants in patients with MDD. An analysis of headto-head trials comparing various second-generation antidepressants showed that the relative benefit, in terms of response, was comparable between trazodone and other second-generation antidepressants, including SSRIs, SNRIs and bupropion [20].

A small study $(\mathrm{n}=27)$ comparing the antidepressant efficacy and safety of trazodone and the SSRI fluoxetine in geriatric patients with depression reported similar improvements in HAM-D scores after 6 weeks of treatment [54]. Significant improvements from baseline in HAM-D scores were also seen with trazodone IR (dose range $50-400 \mathrm{mg} /$ day) and fluoxetine (dose range $20-40 \mathrm{mg} /$ day) in a larger randomized, double-blind study $(\mathrm{n}=126)$ of outpatients with MDD-these improvements in clinical efficacy were similar between the two treatment groups, but HAM-D sleep disturbance scores improved significantly more in the trazodone group than in the fluoxetine group ( -2.7 vs. $1.6 ; p=0.001)$ [37].

More recently, two similar European multicentre, double-blind, randomized trials compared the trazodone prolonged-release twice-daily formulation with paroxetine [39] and sertraline [41] in patients with MDD. Efficacy was assessed by the measurement of changes from baseline in HAM-D, Montgomery Åsberg Depression Rating Scale (MADRS) and Clinical Global Impression-Severity (CGIS) scores after 6 weeks of treatment. The results of these two studies indicated that trazodone prolonged release was as effective as paroxetine and sertraline in reducing depressive symptoms and promoting remission; trazodone may also have advantages for patients with major depression who have sleeping difficulties or show prevalent sleep disturbances [39, 41].

The efficacy of SNRI venlafaxine was compared with that of trazodone IR in a double-blind, randomized, placebo-controlled trial of 225 patients with MDD [38]. In general, both trazodone (dose range $150-400 \mathrm{mg}$ /day following the titration phase) and venlafaxine (dose range 75-200 mg/day) were significantly more effective than placebo according to changes in HAM-D scores. However, trazodone was associated with a greater improvement in the HAM-D-related sleep disturbance factor than venlafaxine, whereas greater improvements in cognitive disturbance and retardation factors were seen with venlafaxine [38].

In contrast to these findings, a double-blind, randomized study of patients with moderate-to-severe MDD demonstrated that the SNRI mirtazapine was associated with 


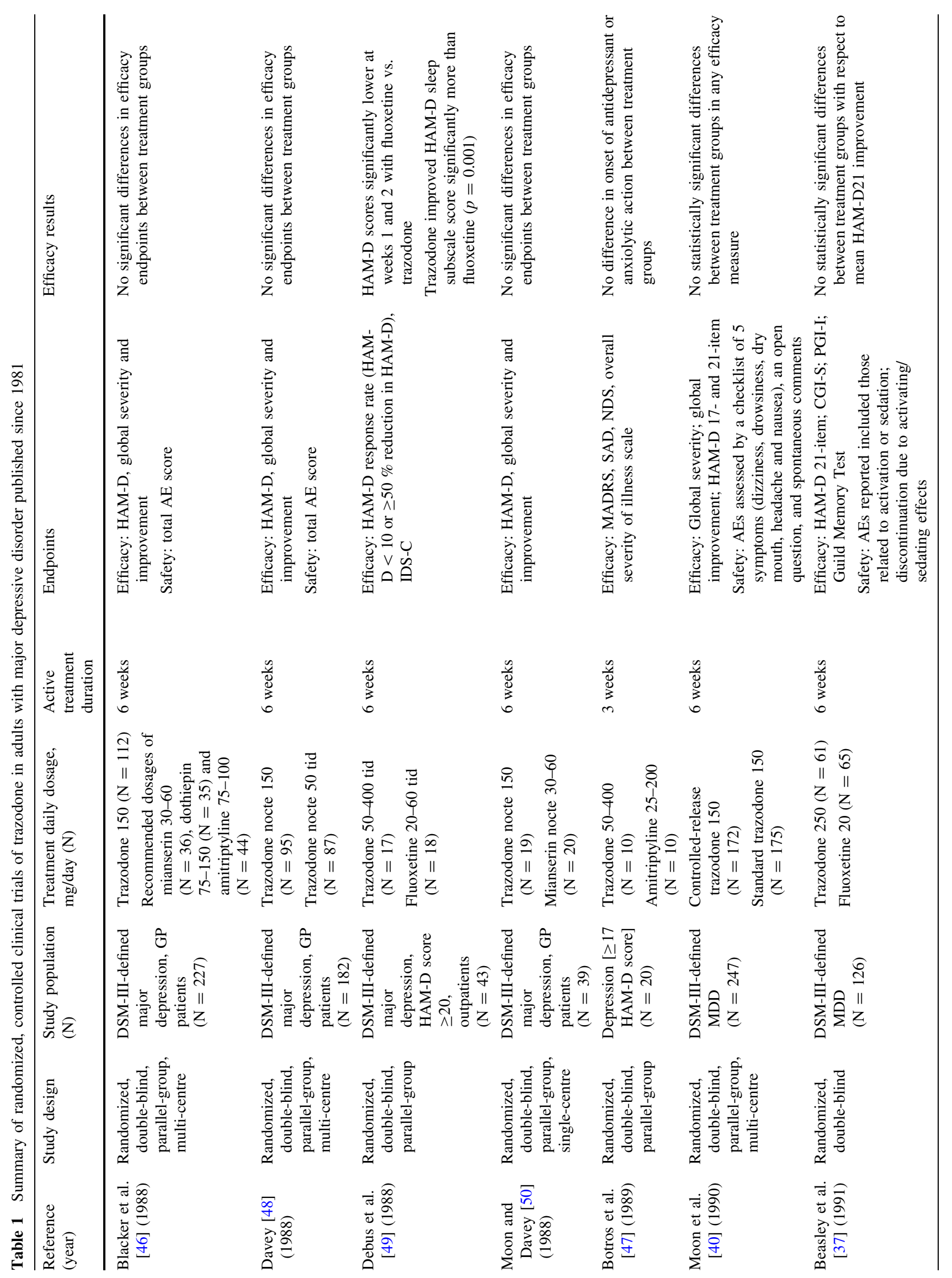




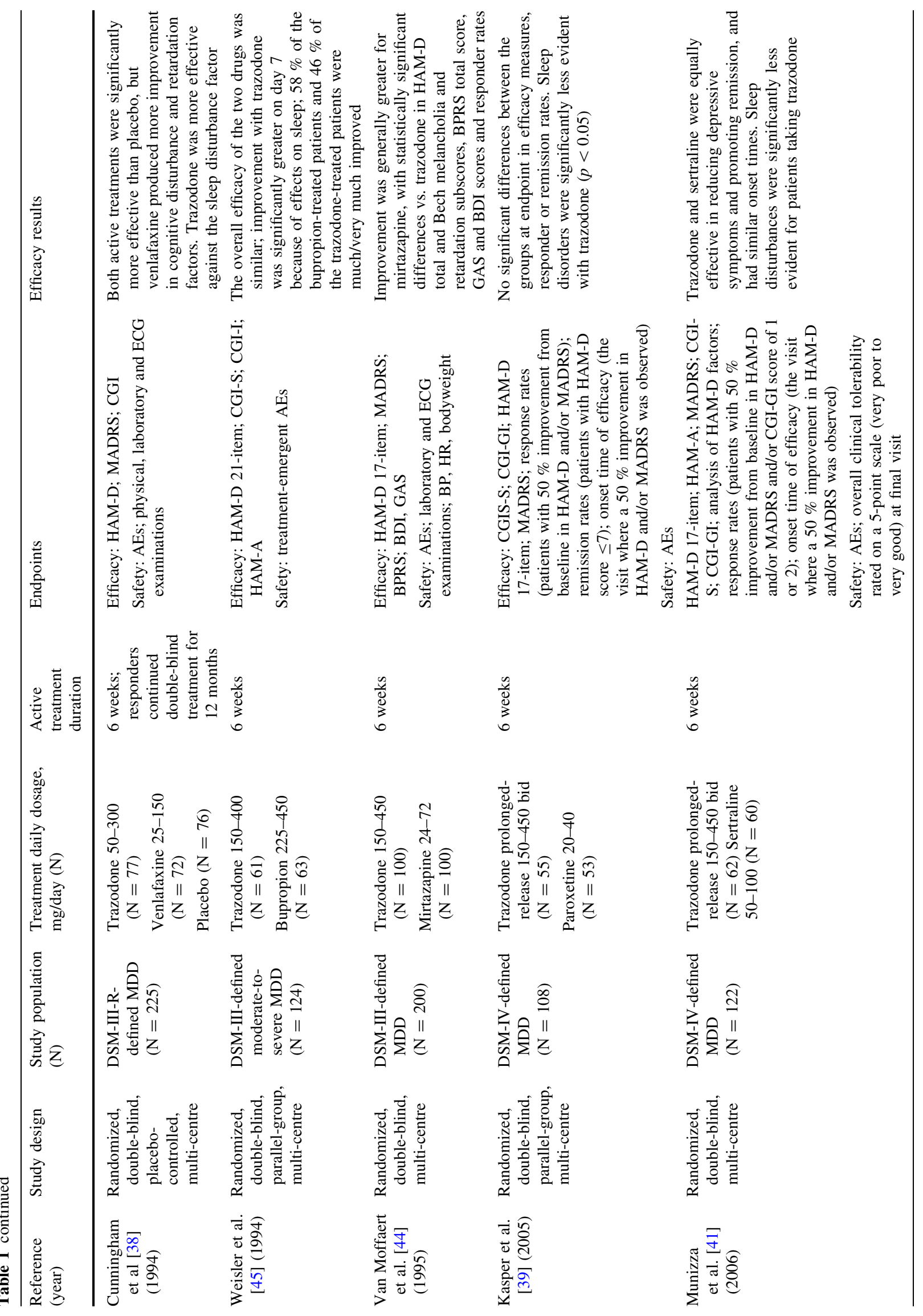




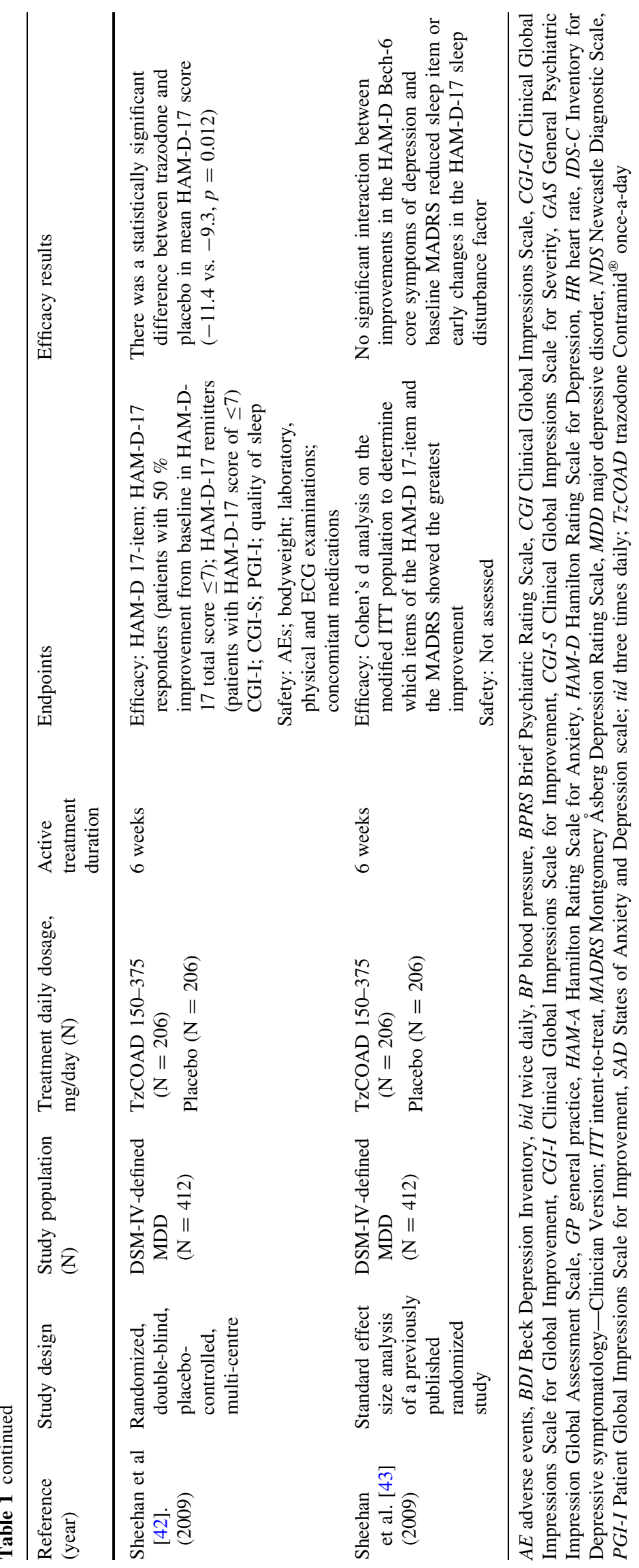


greater improvements in HAM-D scores compared with trazodone after 6 weeks of treatment [44].

Trazodone was compared with the noradrenaline and dopamine reuptake inhibitor bupropion in a double-blind, randomized trial of outpatients with moderate-to-severe MDD [45]. After 6 weeks, overall efficacy according to HAM-D and CGI-S scores was similar between the trazodone IR and bupropion groups. However, improvements in HAM-D and CGI-S scores on day 7 were significantly greater with trazodone versus bupropion due to the beneficial effects on sleep with trazodone. At the end of treatment, $46 \%$ and $58 \%$ of patients were considered to be much/very much improved in the trazodone and bupropion groups, respectively [45].

\subsection{Trazodone Prolonged-Release Formulations}

The prolonged-release formulation (Roussel Laboratories Ltd.) was compared with standard trazodone IR in a double-blind, randomized study of 347 general practice patients with MDD [40]. After 6 weeks of treatment (150 mg/day given at bedtime for both treatment arms), significant improvements from baseline in global severity, global improvement and HAM-D scores were seen in both treatment groups. The difference of these improvements was not statistically significant between trazodone prolonged release and trazodone IR, but small treatment differences in efficacy measures favoured patients who received trazodone prolonged release. Safety, tolerability and compliance did not differ significantly between the two treatment arms, demonstrating that the new formulation was effective and safe [40].

The efficacy and safety of TzCOAD was evaluated in a double-blind, randomized, placebo-controlled study in 412 patients with MDD (6 weeks' treatment, dose range from 150 to $375 \mathrm{mg} /$ day). The mean maximum daily dose of TzCOAD administered during the study was $310 \mathrm{mg}$ [42]. The improvement in HAM-D scores were significantly greater with TzCOAD than with placebo-this difference was already statistically significant after the first week of treatment and was maintained throughout the study [42]. Moreover, there was a higher percentage of HAMD-17 responders and a greater decrease in the change from baseline in the HAMD-17 depressed-mood item, CGI-S and MADRS total score. HAM-D items with the greatest improvement were insomnia items, feelings of guilt and depressed mood, while in the MADRS, the greatest improvement was seen in reduced sleep, inner tension, reported sadness and suicidal thoughts. Notably, the antidepressant efficacy of TzCOAD was independent of the baseline severity of insomnia and of the improvement in insomnia. TzCOAD was also well tolerated; the most frequent adverse events were headache and somnolence.
There were no serious treatment-related adverse events or clinically significant ECG or laboratory abnormalities [43]. These results suggest that TzCOAD-the prolongedrelease, once-a-day formulation of trazodone-may be an effective monotherapy option in patients with MDD, when given at the appropriate therapeutic dose (up to $375 \mathrm{mg}$ / day).

\subsection{Trazodone in Special Patient Populations}

Trazodone has undergone investigation for the treatment of MDD in various patient populations, including the elderly, paediatric patients and those with renal impairment.

In elderly patients with MDD, comparable efficacy was reported between trazodone and the TCA amitriptyline [51]. Two double-blind, randomized studies comparing trazodone and the SSRI fluoxetine also reported similar antidepressant efficacy between the two study treatments [37, 54]. Furthermore, fluoxetine was associated with a higher incidence of activating adverse effects (agitation, anxiety, nervousness, insomnia), compared with trazodone [37]. In contrast, sedating effects were more commonly reported with trazodone therapy versus fluoxetine [37].

Trazodone prolonged-release (Roussel Laboratories Ltd.) was evaluated in elderly patients with depression [55]. After 4 weeks of treatment, both controlled-release and conventional formulations of trazodone (both given at night-time as single daily doses starting at $100 \mathrm{mg}$ and increased to $200 \mathrm{mg}$ /day based on tolerability) were similar in efficacy, as measured by changes from baseline in HAM-D and global assessments of the severity of depression scale scores [55]. Fewer adverse effects were reported during the first week of treatment in patients receiving the controlled-release formulation.

Patients often experience their first episode of MDD during early childhood, prior to puberty or adolescence [56]. To date, there are no data on the use of trazodone in children and adolescents with MDD. In a small open-label study of ten children with chronic tic and Tourette's syndrome, the combination of haloperidol and trazodone was shown to improve clinical symptoms effectively [57]. At study end, the Yale Global Tic Severity Scale score was significantly reduced from baseline, and no adverse effects were reported. However, it should be noted that trazodone is not recommended in children below the age of 18 years.

Trazodone is extensively metabolized in the liver, but the effects of trazodone in patients with renal or hepatic impairment have not been well studied. An early study conducted in the late 1970s assessed the effects of 12 days' treatment with trazodone $(75 \mathrm{mg})$ in patients with mixed neuroses and normal or impaired renal function [58]. Although higher serum concentrations of trazodone were observed in patients with renal impairment, compared to 
those with normal renal function, these differences were not statistically significant [58]. As a result, the authors concluded that renal impairment is not a contraindication of treatment with low-dose trazodone [58]. A recent case of severe liver toxicity resulting in fulminant hepatic failure has been reported following treatment with venlafaxine and trazodone for 4 months [59].

Given the available data on the use of trazodone in patients with renal or hepatic impairment, trazodone product labelling advises careful dosing and regular monitoring in patients with hepatic impairment, particularly in cases of severe hepatic impairment, and severe renal impairment (usually, no dosage adjustment is necessary for mild to moderate renal impairment) [31-33].

\subsection{Tolerability of Trazodone}

Trazodone is generally well tolerated for the treatment of MDD, with the most common adverse effects being drowsiness (somnolence/sedation), headache, dizziness and dry mouth [4].

Drowsiness is the most common adverse effect of trazodone, with a reported incidence in depressed patients ranging from $5.6 \%$ to $22.5 \%$ (latter estimated from figure) $[60,61]$.

Trazodone has minimal anticholinergic activity [62]. However, an increased risk of orthostatic hypotension may be associated with trazodone, particularly in elderly patients or those with pre-existing heart disease [4]. This effect, due to adrenergic $\alpha_{1}$-receptor blockade, is transient and related to plasma drug concentration [63].

At toxic plasma concentrations, trazodone may be associated with prolongation of the corrected QT interval (QTc) and torsade de pointes [64]. Even with therapeutic doses, several cases of life-threatening cardiac arrhythmias, including ventricular tachycardia [65-67] have been reported in clinical and preclinical studies [68]. Data suggest that prolongation of the QT interval is related to the interaction of trazodone with hERG potassium channels $[62,69]$. Concomitant use of trazodone with drugs known to exert cardiac toxicity or to prolong the QT interval should be avoided, because it could increase the risk of ventricular arrhythmias, including torsade de pointes.

Trazodone may also be associated with rare occurrences of priapism [70-72]. For this reason, trazodone should be used with caution in men who have conditions that might predispose them to priapism (e.g. sickle cell anaemia, multiple myeloma, leukaemia, autonomic nervous system dysfunctions and hypercoagulable states), or in men with anatomical deformation of the penis (e.g. angulation, cavernosal fibrosis or Peyronie's disease) [21].

Drug interactions have been reported with cytochrome P450 (CYP) 3A4 enzyme inhibitors, such as erythromycin, ketoconazole and ritonavir, leading to increased plasma concentration of trazodone; conversely, carbamazepine may reduce trazodone plasma concentrations. Concurrent administration with other antidepressant drugs such as TCAs, MAOs or fluoxetine should be avoided due to the risk of developing serotonin syndrome and cardiovascular adverse effects [31]. The interaction between trazodone, citalopram and fluoxetine was studied in 97 patients with depressive syndrome over a 1-year period [73]. Results showed that the use of citalopram and fluoxetine in combination with trazodone had no significant impact on trazodone serum concentrations and no cases of headache, daytime sedation, fatigue or serotonin syndrome were reported during the study.

Antidepressants increase the risk compared with placebo of suicidal thinking and behaviour (suicidality) in children, adolescents and young adults in short-term studies of MDD and other psychiatric disorders [21]. Cases of suicidal ideation and suicidal behaviours have been reported during trazodone therapy or early after treatment discontinuation [31].

\section{5 'Real-World' and Long-Term Data for Trazodone}

Only one study was found to have assessed the use of trazodone in a 'real-world' clinical setting. A semi-naturalistic study evaluating the addition of trazodone to existing venlafaxine treatment reported improved MADRS scores in 50 depressed patients with insomnia [74].

Despite the availability of trazodone for approximately 40 years, long-term efficacy data on its use in MDD and from studies directly assessing the quality of life of trazodone appear to be lacking.

The efficacy and safety of long-term therapy with trazodone IR or imipramine was evaluated in a double-blind, randomized study of 44 outpatients with depression [75]. After 12 months of treatment, trazodone was well tolerated and was associated with significantly greater improvements in HAM-D and CGI scores. Furthermore, a continued clinical benefit was seen in 12 patients who had received open-label trazodone for up to 3 years [75]. In a second double-blind, randomized, placebo-controlled study, the safety and efficacy of trazodone IR and venlafaxine was evaluated in patients with MDD. Of the 149 patients who completed the initial 6-week treatment phase, 96 were classified as clinical responders (CGI score of 1 or 2) and entered a 1-year, double-blind extension phase [38]. Although no efficacy results were reported during the extension phase, a higher proportion of venlafaxine-treated patients entered the extension phase, compared with trazodone IR- and placebo-treated patients (51\% vs. $39 \%$ and $38 \%$, respectively) [38]. Furthermore, the rate of treatment 


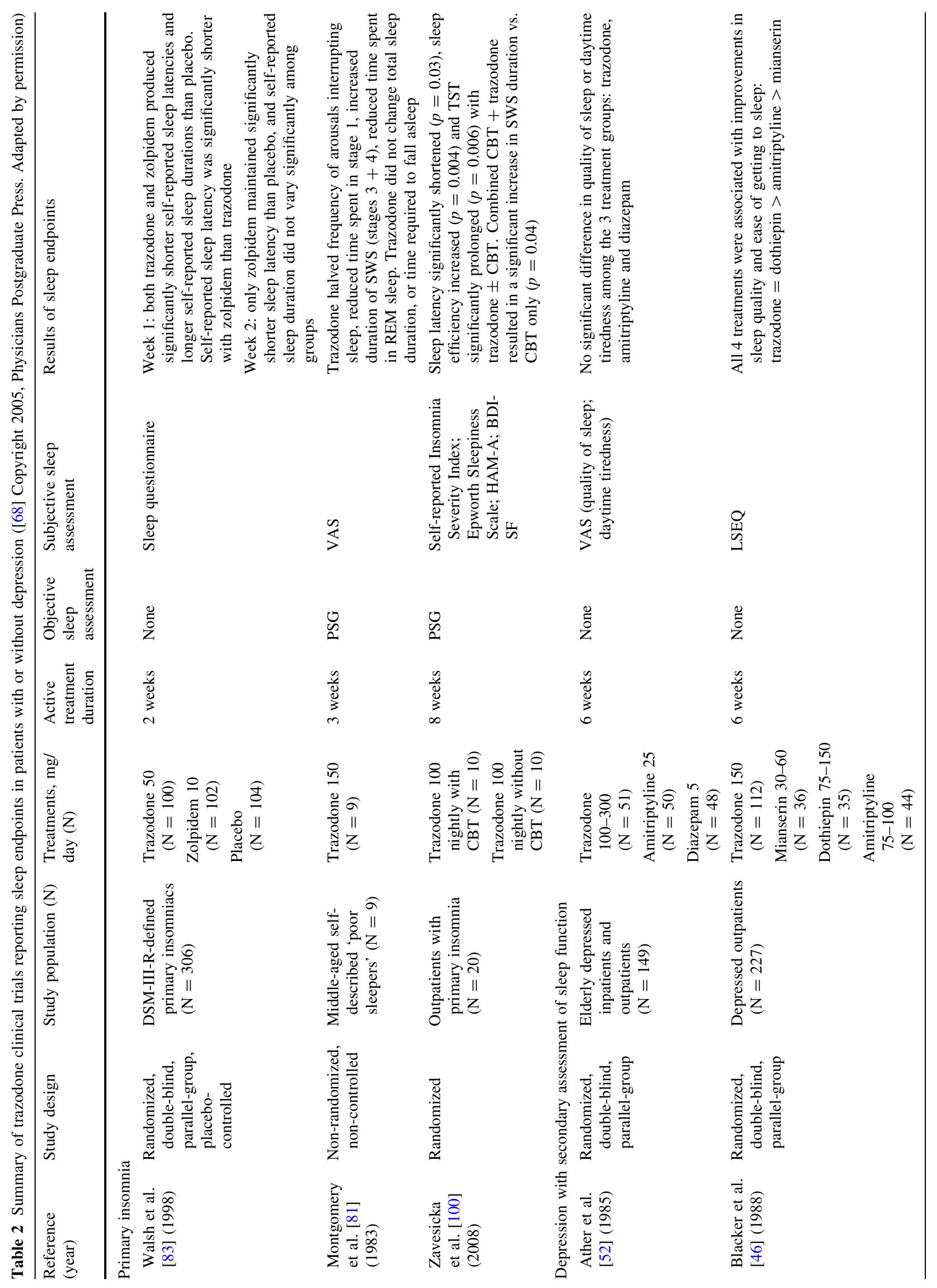




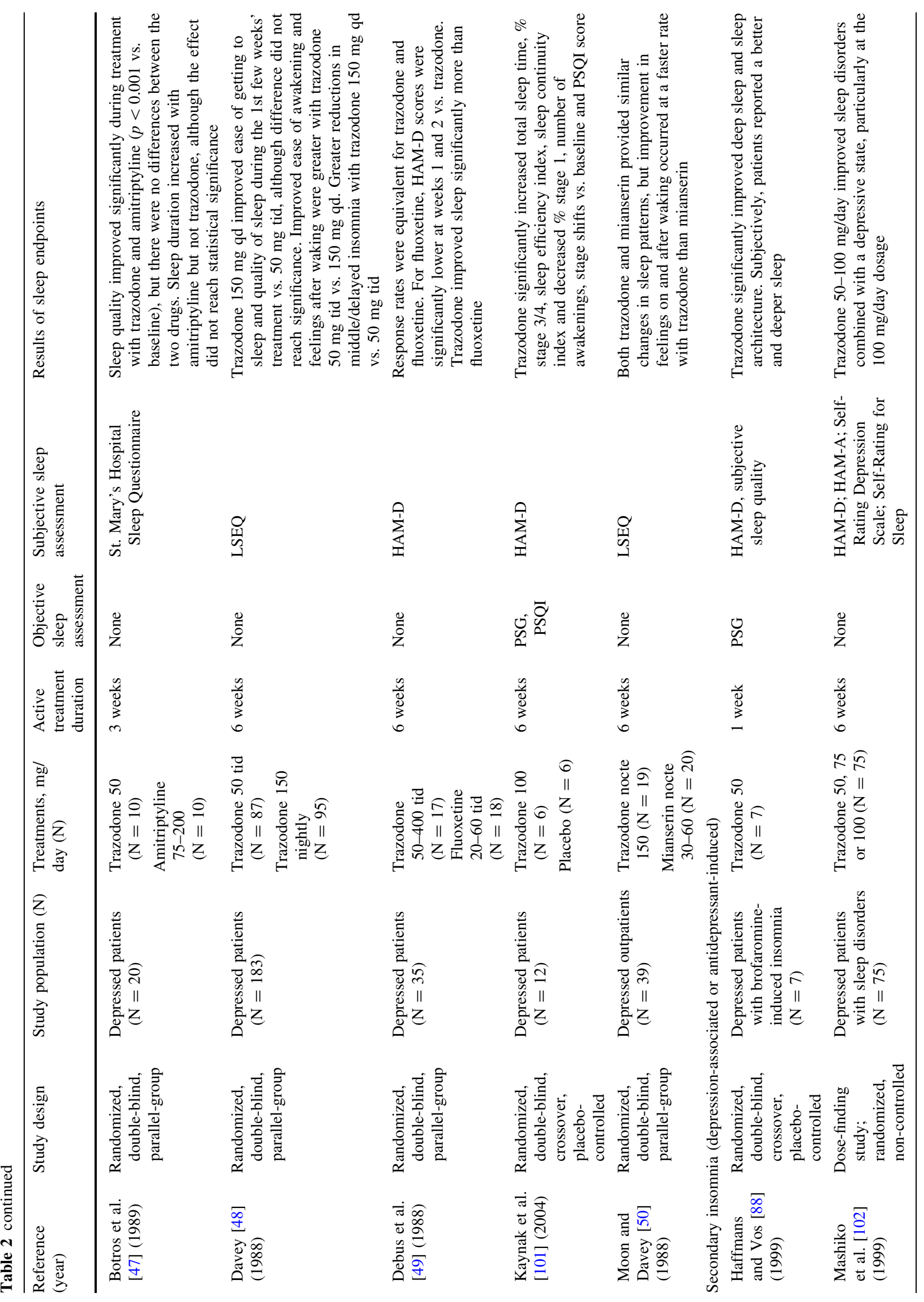




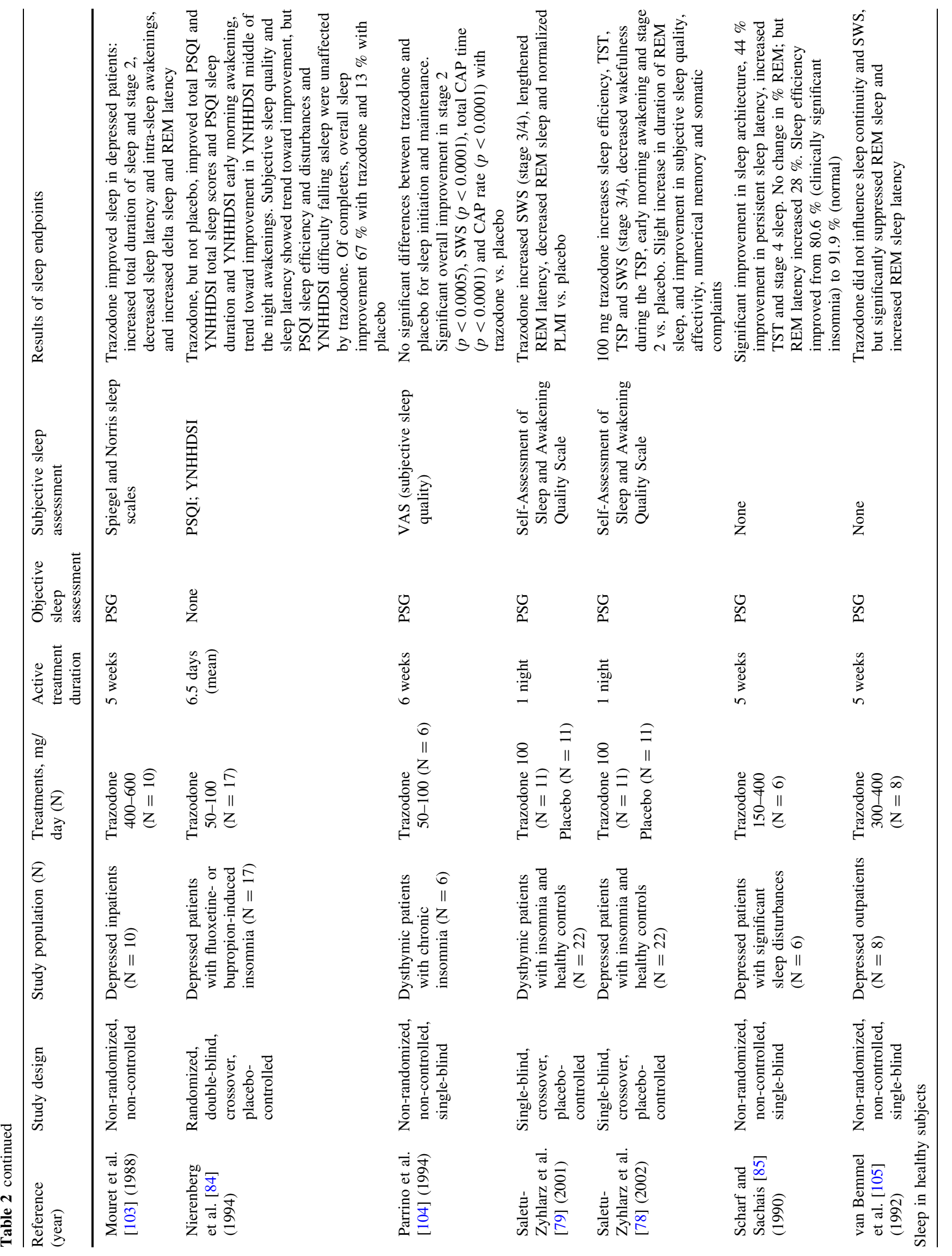




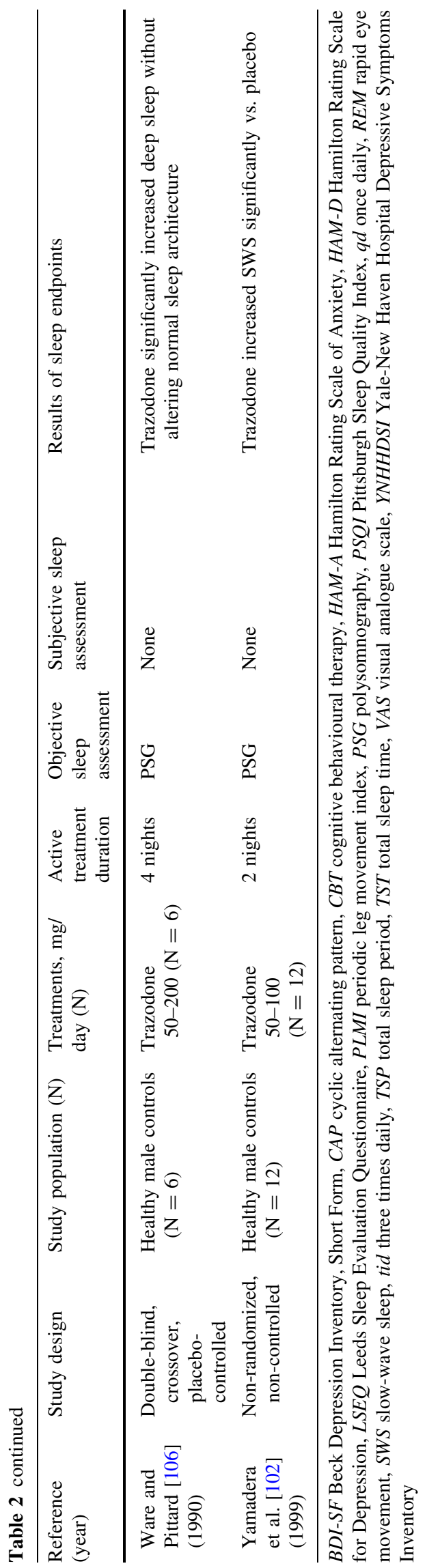

discontinuation for any reason was significantly lower with venlafaxine versus trazodone IR, but no significant differences were seen in discontinuations due to adverse effects.

Based on the limited data available, trazodone may be effective and generally well tolerated in the 'real-world' setting. However, larger controlled studies with a longterm follow-up are required to confirm these findings.

\section{Use of Trazodone in Other Psychiatric Disorders}

In most of the countries where it is marketed, trazodone has only been approved for the treatment of patients with MDD, but this medication has frequently been used for a broad spectrum of psychiatric disorders. As previously described, the pharmacological properties of trazodone are unique among antidepressants, with its mixed serotonergic and adrenolytic activity making trazodone an attractive offlabel treatment option for multiple disorders, including insomnia, anxiety, behavioural disorders associated with dementia and Alzheimer's disease, substance abuse, schizophrenia, eating disorders and fibromyalgia [76].

However, the most frequent off-label use of trazodone is the treatment of insomnia in patients with or without depression [22].

\subsection{Insomnia}

Insomnia incidence and its medical importance is often underestimated, especially in the elderly population, in which it is associated with a significant increase in morbidity and mortality, as well as with an increase in admission to nursing homes [77].

Trazodone is widely used in insomnia in place of benzodiazepines, due its anxiolytic action and its ability to normalize sleep patterns, as demonstrated in depressed patients $[43,78,79]$.

Consequently, the off-label use of trazodone for the treatment of primary or secondary insomnia is currently the most frequent reason for its prescription in the USA [22], where trazodone is the second-most commonly prescribed agent for treating insomnia [80]. At doses lower than those used for the treatment of depression, the hypnotic action of trazodone is thought to be attributed primarily to antagonism of $5-\mathrm{HT}_{2 \mathrm{~A}}$ receptors, $\mathrm{H}_{1}$ receptors and $\alpha_{1}$-adrenergic receptors [22].

Table 2 summarizes clinical trials of trazodone that reported sleep endpoints in patients with or without depression. Early clinical studies demonstrated the potential use of trazodone as a treatment option for insomnia [81, 82]. The effectiveness of trazodone was further established in the 1990s both in patients with primary insomnia [61, 83 ] and in those with insomnia associated with a depressive 
state [84-86]. The results of comparative clinical studies evaluating the use of trazodone as a hypnotic agent for insomnia in patients with depression showed that it was at least as effective as SSRIs (fluoxetine) [37, 87] and MAOIs (brofaromine) [88] in relieving symptoms of insomnia.

Trazodone is particularly effective in the reduction of sleep disturbance in depressed patients due to its sedative effects [43]. Notably, clinical data related to the prolongedrelease, once-a-day formulation show that the antidepressant efficacy of trazodone is independent of baseline insomnia severity (MADRS reduced sleep item) and independent of both the overall improvement in insomnia and the reduction in disturbed sleep as shown by the HAMD-17 sleep disturbance item. According to the authors, the anti-insomnia effect of TzCOAD was not driving the antidepressant effect, which was largely independent of the effectiveness of trazodone on the insomnia parameters [43].

Despite the increasing off-label use of trazodone for insomnia, it should be noted that there are limited clinical data in the literature supporting such widespread use, particularly in non-depressed patients. Clinical trials that explored the use of trazodone in insomnia were mostly short in duration. Reports in normal volunteers and subjects with a history of drug abuse comparing trazodone, triazolam and zolpidem seem to suggest that trazodone (dose range 100-300 mg) may have less potential for misuse among prior drug abusers [89]. Trazodone also had less performance-impairing effects, although it should be noted that these were acute studies of daytime administration [90].

Caution should be used when administering trazodone to the elderly, due to its association with potentially serious, dose-related adverse effects, including daytime sedation, orthostatic hypotension and priapism [91]. Therefore, further large, long-term controlled studies should be performed to confirm the efficacy and safety of trazodone in the treatment of insomnia without MDD.

\subsection{Anxiety Disorders}

Patients with depression may often suffer from additional anxiety disorders, including panic disorder and post-traumatic stress disorder (PTSD) [92]. Pharmacological treatment of these anxiety disorders are comprised of two main drug classes, benzodiazepines and antidepressants $[4,5]$. Due to its hypnotic/sedating effects, trazodone has been the subject of research over the years for the treatment of anxiety disorders.

Trazodone has been shown to be effective in patients with generalized anxiety disorder (GAD) [93], and comparable efficacy between trazodone, imipramine and diazepam was reported in a double-blind, randomized, placebocontrolled trial [94].
Although the first-line treatment option for PTSD is SSRI therapy, non-anticholinergic drugs such as trazodone may be used if SSRIs are ineffective or intolerable. In a small study of six patients with combat-related PTSD, trazodone (50-400 mg) was associated with improvements from baseline in Total Clinician-Administered PTSD Scale and self-reported Davidson Trauma Scale scores [95]. A survey of 60 patients with PTSD, trazodone therapy (50-200 mg), resulted in a decrease in nightmares and improvements in initiating and maintaining sleep [96].

Limited and conflicting data are available for the treatment of panic disorders with trazodone. In some cases, trazodone has been shown to improve symptoms associated with clinical manifestations of the disorder (i.e. GAD, phobias, depression and avoidance conduct) [97], while in others, trazodone has been reported to be ineffective and poorly tolerated [98].

\section{Ongoing and Planned Clinical Trials of Trazodone}

Currently, there is one ongoing clinical trial exploring the off-label use of trazodone IR as a hypnotic agent in patients with chronic insomnia [99]. It is an open-label, randomized study comparing 3 months of treatment with trazodone IR (50 mg) with cognitive behavioural therapy in patients with chronic insomnia [99]. The primary endpoint of this study will be the change from baseline in objective sleep duration, as measured by polysomnography and actigraphy.

A randomized, double-blind study that aims to compare the efficacy and safety of the new trazodone once a day (TzCOAD) formulation and venlafaxine extended release in patients with MDD is planned in Europe [107]. The trial is expected to enrol a total of 360 patients that will be evaluated for efficacy (HAM-D score, as primary endpoint, after 8 weeks of treatment) and safety. This study has been designed to confirm the efficacy and safety of TzCOAD in patients with MDD versus a worldwide standard reference, venlafaxine extended release. In a previous placebo-controlled trial [36], TzCOAD was shown to be as effective as monotherapy in patients with MDD; this trial should provide further evidence of its potential as monotherapy in MDD and for improvement of sleep in depressed patients.

Larger randomized, placebo-controlled clinical trials are needed to establish the clinical benefit of trazodone in offlabel indications, such as primary insomnia.

\section{Conclusions}

Trazodone is currently approved for the treatment of MDD in adults. Although trazodone has been on the market for over 40 years, the recent approval of a once-a-day, 
prolonged-release formulation may boost its clinical utilization in MDD. The multifunctional properties and mechanisms of action of the SARI trazodone enable this drug to control a range of depression-related symptoms, while avoiding adverse effects, such as insomnia, that are often seen along with SSRI treatment. Although trazodone is often used at a low dose as a sedative-hypnotic in depressed patients (as monotherapy or in combination with other antidepressants), as well as in conditions other than depression (i.e. primary insomnia), clinical evidence supporting its use in these settings is limited and further studies should be implemented.

Overall, trazodone is an effective and well tolerated SARI, with an important role in the current treatment of MDD. Trazodone is appreciated worldwide not only for its clinical effectiveness in controlling a wide range of symptoms of depression, but also for the absence of negative effects on sleep-both as monotherapy and in combination regimens. Furthermore, the new prolongedrelease, once-a-day formulation may provide further optimization of its antidepressant efficacy and safety and may improve treatment compliance in MDD patients. The marketing approval process for this formulation is ongoing in several EU countries.

Acknowledgements Medical writing assistance was provided by Maxwell Chang and Claire Pouwels of inScience Communications, Springer Healthcare. This support was funded by Angelini, Italy. AF is/has been a consultant and/or a speaker for and/or has received grants from Angelini, AstraZeneca, Bristol-Myers Squibb, Boehringer Ingelheim, Pfizer, Eli Lilly, Janssen, Lundbeck, Novartis, Otsuka and Sigma Tau. SK has received grant/research support from Bristol Myers-Squibb, Eli Lilly, GlaxoSmithKline, Lundbeck, Organon, Sepracor and Servier; has served as a consultant or on advisory boards for AstraZeneca, Bristol-Myers Squibb, Eli Lilly, GlaxoSmithKline, Janssen, Lundbeck, Merck Sharp and Dome (MSD), Novartis, Organon, Pfizer, Schwabe, Sepracor and Servier; and has served on speakers' bureaus for Angelini, AstraZeneca, Bristol Myers-Squibb, Eli Lilly, Janssen, Lundbeck, Pfizer, Pierre Fabre, Schwabe, Sepracor and Servier. AC is an employee of Angelini SpA, Italy. MCO has no conflicts of interest to declare.

Open Access This article is distributed under the terms of the Creative Commons Attribution Noncommercial License which permits any noncommercial use, distribution, and reproduction in any medium, provided the original author(s) and the source are credited.

\section{References}

1. World Health Organization. Depression. http://www.who.int/men tal_health/management/depression/definition/en/ (2012). Accessed 13 May 2012.

2. Nutt DJ, Davidson JR, Gelenberg AJ, et al. International consensus statement on major depressive disorder. J Clin Psychiatry. 2010;71(Suppl E1):e08.

3. Prince M, Patel V, Saxena S, et al. No health without mental health. Lancet. 2007;370(9590):859-77.
4. American Psychiatric Association. Practice guideline for the treatment of patients with major depressive disorder. 3rd ed. Arlington: American Psychiatric Association; 2010.

5. Bauer M, Bschor T, Pfennig A, et al. World Federation of Societies of Biological Psychiatry (WFSBP) guidelines for biological treatment of unipolar depressive disorders in primary care. World J Biol Psychiatry. 2007;8(2):67-104.

6. Davidson JR. Major depressive disorder treatment guidelines in America and Europe. J Clin Psychiatry. 2010;71(Suppl E1):e04.

7. Harter $\mathrm{M}$, Klesse $\mathrm{C}$, Bermejo I, et al. Unipolar depression: diagnostic and therapeutic recommendations from the current S3/National Clinical Practice Guideline. Dtsch Arztebl Int. 2010;107(40):700-8.

8. National Institute for Health and Clinical Excellence. Depression: the treatment and management of depression in adults. http://www.nice.org.uk/nicemedia/live/12329/45888/45888.pdf (2009). Accessed 14 Aug 2012.

9. Thase ME. Evaluating antidepressant therapies: remission as the optimal outcome. J Clin Psychiatry. 2003;64(Suppl 13): $18-25$.

10. Chang T, Fava M. The future of psychopharmacology of depression. J Clin Psychiatry. 2010;71(8):971-5.

11. Machado M, Iskedjian M, Ruiz I, Einarson TR. Remission, dropouts, and adverse drug reaction rates in major depressive disorder: a meta-analysis of head-to-head trials. Curr Med Res Opin. 2006;22(9):1825-37.

12. Trivedi MH, Rush AJ, Wisniewski SR, et al. Evaluation of outcomes with citalopram for depression using measurementbased care in STAR*D: implications for clinical practice. Am J Psychiatry. 2006;163(1):28-40.

13. Nierenberg AA, Keefe BR, Leslie VC, et al. Residual symptoms in depressed patients who respond acutely to fluoxetine. J Clin Psychiatry. 1999;60(4):221-5.

14. Clayton AH, Pradko JF, Croft HA, et al. Prevalence of sexual dysfunction among newer antidepressants. J Clin Psychiatry. 2002;63(4):357-66.

15. Fava M. Weight gain and antidepressants. J Clin Psychiatry. 2000;61(Suppl 11):37-41.

16. Fava M. Daytime sleepiness and insomnia as correlates of depression. J Clin Psychiatry. 2004;65(Suppl 16):27-32.

17. Fava M, Hoog SL, Judge RA, et al. Acute efficacy of fluoxetine versus sertraline and paroxetine in major depressive disorder including effects of baseline insomnia. J Clin Psychopharmacol. 2002;22(2):137-47.

18. Thase ME. Treatment issues related to sleep and depression. J Clin Psychiatry. 2000;61(Suppl 11):46-50.

19. Feighner JP, Boyer WF. Overview of USA controlled trials of trazodone in clinical depression. Psychopharmacology. 1988; 95(Suppl):S50-3.

20. Gartlehner G, Gaynes BN, Hansen RA, et al. Comparative benefits and harms of second-generation antidepressants: background paper for the American College of Physicians. Ann Intern Med. 2008;149(10):734-50.

21. Extended-release trazodone (Oleptro) for depression. Med Lett Drugs Ther. 2010;52(1351):91-2.

22. Stahl SM. Mechanism of action of trazodone: a multifunctional drug. CNS Spectr. 2009;14(10):536-46.

23. Brogden RN, Heel RC, Speight TM, Avery GS. Trazodone: a review of its pharmacological properties and therapeutic use in depression and anxiety. Drugs. 1981;21(6):401-29.

24. Odagaki Y, Toyoshima R, Yamauchi T. Trazodone and its active metabolite $\mathrm{m}$-chlorophenylpiperazine as partial agonists at $5-\mathrm{HT}_{1 \mathrm{~A}}$ receptors assessed by [35S]GTPgammaS binding. J Psychopharmacol. 2005;19(3):235-41.

25. Stahl SM. Stahl's essential psychopharmacology. 3rd ed. New York (NY): Cambridge University Press; 2008. 
26. Marek GJ, Carpenter LL, McDougle CJ, Price LH. Synergistic action of $5-\mathrm{HT}_{2 \mathrm{~A}}$ antagonists and selective serotonin reuptake inhibitors in neuropsychiatric disorders. Neuropsychopharmacology. 2003;28(2):402-12.

27. Nierenberg AA, Cole JO, Glass L. Possible trazodone potentiation of fluoxetine: a case series. J Clin Psychiatry. 1992; 53(3):83-5.

28. Pazzagli M, Giovannini MG, Pepeu G. Trazodone increases extracellular serotonin levels in the frontal cortex of rats. Eur $\mathbf{J}$ Pharmacol. 1999;383(3):249-57.

29. Saper CB, Chou TC, Scammell TE. The sleep switch: hypothalamic control of sleep and wakefulness. Trends Neurosci. 2001;24(12):726-31.

30. Stahl SM. Selective histamine H1 antagonism: novel hypnotic and pharmacologic actions challenge classical notions of antihistamines. CNS Spectr. 2008;13(12):1027-38.

31. Aziende Chimiche Riunite Angelini Francesco (ACRAF SpA). Trittico (trazodone hydrochloride) $75 \mathrm{mg}$ and $150 \mathrm{mg}$ prolongedrelease tablets: summary of the product characteristics. http:// www.angelini.it/public/schedepharma/trittico_rilascio_prolung.htm. Accessed June 152012.

32. Medicines and Healthcare Products Regulatory Agency. Trazodone hydrochloride $50 \mathrm{mg}$ and $100 \mathrm{mg}$ capsules: summary of the product characteristics. http://www.mhra.gov.uk/home/groups/ 1-unit1/documents/websiteresources/con2023774.pdf. Accessed 22 Aug 2012.

33. Oleptro ${ }^{\mathrm{TM}}$ (trazodone hydrochloride) extended-release tablets. P T 2011;36(2):2-18.

34. Rawls WN. Trazodone (Desyrel, Mead-Johnson Pharmaceutical Division). Drug Intell Clin Pharm. 1982;16(1):7-13.

35. Karhu D, Gossen ER, Mostert A, et al. Safety, tolerability, and pharmacokinetics of once-daily trazodone extended-release caplets in healthy subjects. Int J Clin Pharm Ther. 2011;49(12): 730-43.

36. Papakostas GI, Fava M. A meta-analysis of clinical trials comparing the serotonin (5HT)-2 receptor antagonists trazodone and nefazodone with selective serotonin reuptake inhibitors for the treatment of major depressive disorder. Eur Psychiatry. 2007;22(7):444-7.

37. Beasley CM Jr, Dornseif BE, Pultz JA, et al. Fluoxetine versus trazodone: efficacy and activating-sedating effects. J Clin Psychiatry. 1991;52(7):294-9.

38. Cunningham LA, Borison RL, Carman JS, et al. A comparison of venlafaxine, trazodone, and placebo in major depression. J Clin Psychopharmacol. 1994;14(2):99-106.

39. Kasper S, Olivieri L, Di Loreto G, Dionisio P. A comparative, randomised, double-blind study of trazodone prolonged-release and paroxetine in the treatment of patients with major depressive disorder. Curr Med Res Opin. 2005;21(8):1139-46.

40. Moon CA, Laws D, Stott PC, Hayes G. Efficacy and tolerability of controlled-release trazodone in depression: a large multicentre study in general practice. Curr Med Res Opin. 1990;12(3):160-8.

41. Munizza C, Olivieri L, Di Loreto G, Dionisio P. A comparative, randomized, double-blind study of trazodone prolonged-release and sertraline in the treatment of major depressive disorder. Curr Med Res Opin. 2006;22(9):1703-13.

42. Sheehan DV, Croft HA, Gossen ER, et al. Extended-release trazodone in major depressive disorder: a randomized, doubleblind, placebo-controlled study. Psychiatry. 2009;6(5):20-33.

43. Sheehan DV, Rozova A, Gossen ER, Gibertini M. The efficacy and tolerability of once-daily controlled-release trazodone for depressed mood, anxiety, insomnia, and suicidality in major depressive disorder. Psychopharmacol Bull. 2009;42(4):5-22.

44. van Moffaert M, de Wilde J, Vereecken A, et al. Mirtazapine is more effective than trazodone: a double-blind controlled study in hospitalized patients with major depression. Int Clin Psychopharmacol. 1995;10(1):3-9.

45. Weisler RH, Johnston JA, Lineberry CG, et al. Comparison of bupropion and trazodone for the treatment of major depression. J Clin Psychopharmacol. 1994;14(3):170-9.

46. Blacker R, Shanks NJ, Chapman N, Davey A. The drug treatment of depression in general practice: a comparison of nocte administration of trazodone with mianserin, dothiepin and amitriptyline. Psychopharmacology. 1988;95(Suppl):S18-24.

47. Botros WA, Ankier SI, Priest RG, et al. Clinical assessment and performance tasks in depression: a comparison of amitriptyline and trazodone. Br J Psychiatry. 1989;155:479-82.

48. Davey A. A comparison of two oral dosage regimens of $150 \mathrm{mg}$ trazodone in the treatment of depression in general practice. Psychopharmacology. 1988;95(Suppl):S25-30.

49. Debus JR, Rush AJ, Himmel C, et al. Fluoxetine versus trazodone in the treatment of outpatients with major depression. J Clin Psychiatry. 1988;49(11):422-6.

50. Moon CA, Davey A. The efficacy and residual effects of trazodone (150 mg nocte) and mianserin in the treatment of depressed general practice patients. Psychopharmacology. 1988;95(Suppl):S7-13.

51. Altamura AC, Mauri MC, Rudas N, et al. Clinical activity and tolerability of trazodone, mianserin, and amitriptyline in elderly subjects with major depression: a controlled multicenter trial. Clin Neuropharmacol. 1989;12(Suppl 1):S25-33 (S4-7).

52. Ather SA, Ankier SI, Middleton RS. A double-blind evaluation of trazodone in the treatment of depression in the elderly. Br J Clin Pract. 1985;39(5):192-9.

53. Gerner R, Estabrook W, Steuer J, Jarvik L. Treatment of geriatric depression with trazodone, imipramine, and placebo: a double-blind study. J Clin Psychiatry. 1980;41(6):216-20.

54. Falk WE, Rosenbaum JF, Otto MW, et al. Fluoxetine versus trazodone in depressed geriatric patients. J Geriatr Psychiatry Neurol. 1989;2(4):208-14.

55. Bayer AJ, Pathy MS, Cameron A, et al. A comparative study of conventional and controlled-release formulations of trazodone in elderly depressed patients. Clin Neuropharmacol. 1989;12(Suppl 1): S50-5 (discussion S6-7).

56. Birmaher B, Brent DA, Benson RS. Summary of the practice parameters for the assessment and treatment of children and adolescents with depressive disorders: American Academy of Child and Adolescent Psychiatry. J Am Acad Child Adolesc Psychiatry. 1998;37(11):1234-8.

57. Saccomani L, Rizzo P, Nobili L. Combined treatment with haloperidol and trazodone in patients with tic disorders. J Child Adolesc Psychopharmacol. 2000;10(4):307-10.

58. Catanese B, Dionisio A, Barillari G, De Martino C. A comparative study of trazodone serum concentrations in patients with normal or impaired renal function. Boll Chim Farm. 1978;117(7):424-7.

59. Detry O, Delwaide J, De Roover A, et al. Fulminant hepatic failure induced by venlafaxine and trazodone therapy: a case report. Transplant Proc. 2009;41(8):3435-6.

60. Agnoli A, De Gregorio M, Dionisio A. Trazodone, a review of clinical literature and personal experience. Psychopathology. 1984;17(Suppl 2):88-103.

61. Haria M, Fitton A, McTavish D. Trazodone: a review of its pharmacology, therapeutic use in depression and therapeutic potential in other disorders. Drugs Aging. 1994;4(4):331-55.

62. Burgess CD, Hames TK, George CF. The electrocardiographic and anticholinergic effects of trazodone and imipramine in man. Eur J Clin Pharmacol. 1982;23(5):417-21.

63. Glassman AH. The newer antidepressant drugs and their cardiovascular effects. Psychopharmacol Bull. 1984;20(2):272-9. 
64. de Meester A, Carbutti G, Gabriel L, Jacques JM. Fatal overdose with trazodone: case report and literature review. Acta Clin Belg. 2001;56(4):258-61.

65. Aronson MD, Hafez H. A case of trazodone-induced ventricular tachycardia. J Clin Psychiatry. 1986;47(7):388-9.

66. Vitullo RN, Wharton JM, Allen NB, Pritchett EL. Trazodonerelated exercise-induced nonsustained ventricular tachycardia. Chest. 1990;98(1):247-8.

67. Winkler D, Ortner R, Pjrek E, et al. Trazodone-induced cardiac arrhythmias: a report of two cases. Hum Psychopharmacol. 2006;21(1):61-2.

68. Mendelson WB. A review of the evidence for the efficacy and safety of trazodone in insomnia. J Clin Psychiatry. 2005; 66(4):469-76.

69. Tarantino P, Appleton N, Lansdell K. Effect of trazodone on hERG channel current and QT-interval. Eur J Pharmacol. 2005;510(1-2):75-85.

70. Jayaram G, Rao P. Safety of trazodone as a sleep agent for inpatients. Psychosomatics. 2005;46(4):367-9.

71. Stryjer R, Strous RD, Bar F, et al. Treatment of neurolepticinduced akathisia with the $5-\mathrm{HT}_{2 \mathrm{~A}}$ antagonist trazodone. Clin Neuropharmacol. 2003;26(3):137-41.

72. Thompson JW Jr, Ware MR, Blashfield RK. Psychotropic medication and priapism: a comprehensive review. J Clin Psychiatry. 1990;51(10):430-3.

73. Prapotnik M, Waschgler R, Konig P, et al. Therapeutic drug monitoring of trazodone: are there pharmacokinetic interactions involving citalopram and fluoxetine? Int $\mathrm{J}$ Clin Pharm Ther. 2004;42(2):120-4.

74. Bertschy G, Ragama-Pardos E, Muscionico M, et al. Trazodone addition for insomnia in venlafaxine-treated, depressed inpatients: a semi-naturalistic study. Pharmacol Res. 2005;51(1):79-84.

75. Fabre LF Jr, Feighner JP. Long-term therapy for depression with trazodone. J Clin Psychiatry. 1983;44(1):17-21.

76. Bossini L, Casolaro I, Koukouna D, et al. Off-label uses of trazodone: a review. Expert Opin Pharmacother 2012;13(12):1707-17.

77. Ancoli-Israel S. Insomnia in the elderly: a review for the primary care practitioner. Sleep 2000;23(Suppl 1):S23-30 (discussion S6-8).

78. Saletu-Zyhlarz GM, Abu-Bakr MH, Anderer P, et al. Insomnia in depression: differences in objective and subjective sleep and awakening quality to normal controls and acute effects of trazodone. Prog Neuropsychopharmacol Biol Psychiatry. 2002;26(2):249-60.

79. Saletu-Zyhlarz GM, Abu-Bakr MH, Anderer P, et al. Insomnia related to dysthymia: polysomnographic and psychometric comparison with normal controls and acute therapeutic trials with trazodone. Neuropsychobiol. 2001;44(3):139-49.

80. Rosenberg RP. Sleep maintenance insomnia: strengths and weaknesses of current pharmacologic therapies. Ann Clin Psychiatry. 2006;18(1):49-56.

81. Montgomery I, Oswald I, Morgan K, Adam K. Trazodone enhances sleep in subjective quality but not in objective duration. Br J Clin Pharmacol. 1983;16(2):139-44.

82. Wheatley D. Trazodone: alternative dose regimens and sleep. Pharmatherapeutica. 1984;3(9):607-12.

83. Walsh JB, Erman M, Erwin CW, et al. Subjective hypnotic efficacy of trazodone and zolpidem in DSM-III-R primary insomnia. Hum Psychopharmacol. 1998;13:191-8.

84. Nierenberg AA, Adler LA, Peselow E, et al. Trazodone for antidepressant-associated insomnia. Am J Psychiatry. 1994; 151(7):1069-72.

85. Scharf MB, Sachais BA. Sleep laboratory evaluation of the effects and efficacy of trazodone in depressed insomniac patients. J Clin Psychiatry. 1990;51(Suppl):13-7.

86. Thase ME. Antidepressant treatment of the depressed patient with insomnia. J Clin Psychiatry. 1999;60(Suppl)17:28-31 (discussion 46-8).
87. Kallepalli BR, Bhatara VS, Fogas BS, et al. Trazodone is only slightly faster than fluoxetine in relieving insomnia in adolescents with depressive disorders. J Child Adolesc Psychopharmacol. 1997;7(2):97-107.

88. Haffmans PM, Vos MS. The effects of trazodone on sleep disturbances induced by brofaromine. Eur Psychiatry. 1999;14(3): 167-71.

89. Rush CR, Baker RW, Wright K. Acute behavioral effects and abuse potential of trazodone, zolpidem and triazolam in humans. Psychopharmacology. 1999;144(3):220-33.

90. Rush CR, Madakasira S, Hayes CA, et al. Trazodone and triazolam: acute subject-rated and performance-impairing effects in healthy volunteers. Psychopharmacology. 1997;131(1):9-18.

91. Pollak CP, Perlick D, Linsner JP, et al. Sleep problems in the community elderly as predictors of death and nursing home placement. J Community Health. 1990;15(2):123-35.

92. Wittchen HU, Lieb R, Wunderlich U, Schuster P. Comorbidity in primary care: presentation and consequences. J Clin Psychiatry. 1999;60(Suppl 7):29-36 (discussion 7-8).

93. Gale CK. The treatment of generalised anxiety disorder: a systematic review. Panminerva Med. 2002;44(4):283-6.

94. Rickels K, Downing R, Schweizer E, Hassman H. Antidepressants for the treatment of generalized anxiety disorder: a placebo-controlled comparison of imipramine, trazodone, and diazepam. Arch Gen Psychiatry. 1993;50(11):884-95.

95. Hertzberg MA, Feldman ME, Beckham JC, Davidson JR. Trial of trazodone for posttraumatic stress disorder using a multiple baseline group design. J Clin Psychopharmacol. 1996;16(4):294-8.

96. Warner MD, Dorn MR, Peabody CA. Survey on the usefulness of trazodone in patients with PTSD with insomnia or nightmares. Pharmacopsychiatry. 2001;34(4):128-31.

97. Mavissakalian M, Perel J, Bowler K, Dealy R. Trazodone in the treatment of panic disorder and agoraphobia with panic attacks. Am J Psychiatry. 1987;144(6):785-7.

98. Charney DS, Woods SW, Goodman WK, et al. Drug treatment of panic disorder: the comparative efficacy of imipramine, alprazolam, and trazodone. J Clin Psychiatry. 1986;47(12):580-6.

99. Milton S, Hershey Medical Center. Efficacy of trazodone vs. cognitive behavioral therapy in patients with chronic insomnia associated with objective short sleep duration [ClinicalTrials.gov identifier NCT01348542]. US National Institutes of Health, ClinicalTrials.gov. http://www.clinicaltrials.gov. Accessed 5 June 2012.

100. Zavesicka L, Brunovsky M, Horacek J, et al. Trazodone improves the results of cognitive behaviour therapy of primary insomnia in non-depressed patients. Neuro Endocrinol Lett. 2008;29(6):895-901.

101. Kaynak H, Kaynak D, Gozukirmizi E, Guilleminault C. The effects of trazodone on sleep in patients treated with stimulant antidepressants. Sleep Med. 2004;5(1):15-20.

102. Yamadera H, Suzuki H, Nakamura S, Endo S. Effects of trazodone on polysomnography, blood concentration and core body temperature in healthy volunteers. Psychiatry Clin Neurosci. 1999;53(2):189-91.

103. Mouret J, Lemoine P, Minuit MP, et al. Effects of trazodone on the sleep of depressed subjects: a polygraphic study. Psychopharmacology. 1988;95(Suppl):S37-43.

104. Parrino L, Spaggiari MC, Boselli M, et al. Clinical and polysomnographic effects of trazodone CR in chronic insomnia associated with dysthymia. Psychopharmacology. 1994;116(4):389-95.

105. van Bemmel AL, Havermans RG, van Diest R. Effects of trazodone on EEG sleep and clinical state in major depression. Psychopharmacology. 1992;107(4):569-74.

106. Ware JC, Pittard JT. Increased deep sleep after trazodone use: a double-blind placebo-controlled study in healthy young adults. J Clin Psychiatry. 1990;51(Suppl):18-22.

107. Data on file, Angelini (2012). 